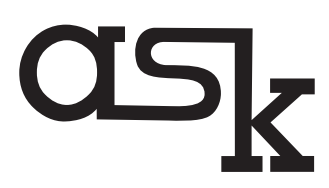

Research \& Methods E-ISSN 2544-0799

ISSN 1234-9224 Vol. 26 (1, 2017): 61-80

The Ohio State University

Columbus, Ohio, USA

Institute of Philosophy and Sociology

Polish Academy of Sciences, Warsaw, Poland www.askresearchandmethods.org

\title{
On the Use of Microsimulation for Investigating Ideological Dissent: Exemplary Analyses of the Values of the European Political Left ${ }^{1}$
}

\author{
Georg P. Mueller \\ University of Fribourg
}

This article presents a new approach to the comparison of the meaning of social or political key terms in different national contexts. Instead of relying on classical statistical instruments such as t-tests of the mean attitudes, the author proposes to analyze value conflicts between the mentioned groups. In international surveys like the European Values Study (EVS) the related conflict data are not directly available but can be generated by microsimulation: for this purpose the article proposes to look at the value differences of randomly matched artificial pairs of respondents. The resulting dyadic data-records correspond to simulated virtual encounters of persons with the same or different opinions about a political issue. In this way it becomes possible to measure the amount and the thematic focus of the value conflicts between the protagonists of a key term in different countries: the absence of conflicts between these groups points to the same meaning of the key term, whereas dissent about its attributes is an indicator of semantic differences. The benchmark for assessing these international inter-group conflicts are the national intra-group conflicts, which are generally underestimated. Consequently, an application of the proposed method to an artificial dataset with systematically varying statistical properties suggests that the traditional t-tests of mean attitudes overestimate the international group differences. By considering the internal ideological variation of the compared groups we probably get a more realistic assessment of their international similarities and differences. Thus we dare to tackle with the proposed virtual encounter method a real world problem: the comparative analysis of the values of the political left in Sweden, France, and the UK on the basis of attitudes gathered in the European Values Study (2008). A major result is that income equality is revealed to be an important common value of the political left in the three countries mentioned. Finally, the article points to the possibility of comparing different intra-national groups with regard to their ideologies. By the virtual encounter method it is possible to focus the analysis on a particular country and compare e.g. its national parties or different generations of partisans.

Keywords: microsimulation; network analysis; virtual encounters; interview data; political semantics; left ideologies. 


\section{INTRODUCTION}

There is an increasing number of international survey projects like the International Social Survey Programme (ISSP 2015), the European Values Study (EVS 2008), or the European Social Survey (ESS 2015), which claim to produce internationally comparable interview data. Important measures taken toward achieving this goal are careful translations into the different national languages of the survey, extended pretests of the questionnaires, etc. (Saris \& Gallhofer 2007, Harkness, Van de Vijver \& Mohler 2003, Harkness 2007, Harkness \& al. 2010). In spite of all these methodological efforts it is still possible that international comparisons of interview answers are impaired by the different meanings of concepts in different countries (Hantrais 2007: 14-15), something which endangers the validity of their measurement.

Left or right politics are important and typical examples of such ambiguous concepts. Their meaning for a nation's citizens depends among other things on the political alternatives in the national party systems, which obviously vary from country to country and often also change over time. In a two-party system like that of the USA left and right have different meanings than in a European multi-party system like that of Germany. Similarly, in countries that have experienced the rise of a new populist right-wing party the meaning of left and right has recently changed. Finally, not all party systems have started in the same historical moment and consequently differ from country to country, as the example of Eastern Europe demonstrates (Lewis 2000).

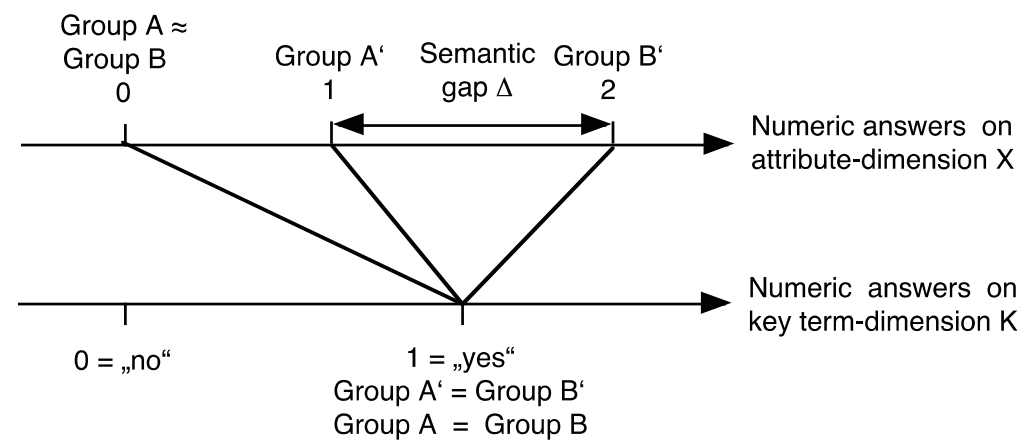

Fig. 1: Tackling the problem of semantic gaps by analyzing the attributes of a social or political key term.

One of the methods for revealing the semantics of ambiguous concepts is the analysis of co-words, which was originally developed in scientometrics in order to categorize the content of scientific papers (Callon \& al. 1993: chap. 7, de Bellis 
2009: 143 ff.). If two groups A and B refer to the same social or political key term, they should assign to it the same co-words, if the key term has for both groups really the same meaning (Smith \& al. 2009). Fig. 1 describes this kind of consensus for a standardized interview, where co-words like e.g. "agree about X", or "disagree about X", etc. are represented by value-labels $0,1,2, \ldots$ of an attributedimension X, which matters for the definition of the key term. Fig. 1 displays also a second situation, where two other groups $\mathrm{A}^{\prime}$ and $\mathrm{B}^{\text {' }}$ assign to the same social or political key term different co-words, represented by different numeric values on the attribute-dimension of this key term. Thus for $\mathrm{A}^{\prime}$ and $\mathrm{B}^{\prime}$ there is a semantic gap $\Delta$, which points to different meanings of the key term for these groups, although the key term has for A' and B' the same numeric value 1 .

Fig. 1 is a simplification in so far as the meaning of a key term generally depends not only on one but on several attribute-dimensions, like e.g. the meaning of being a "good citizen". In order to consider this additional complexity one may of course add to Fig. 1 other attribute-dimensions. However, these polarity profiles are also simplifications, since interview data about groups have always some inter-individual variation, which is often reduced to simple statistical values such as means or medians. One might be tempted to identify the above mentioned semantic gap by just comparing the two groups with regard to these statistical means or medians on one or several attribute-dimensions. In a certain way Fig. 1 represents this kind of simplification with simple statistical measures. This approach obviously bears the risk of ecological fallacies (Crow 2006): there may for example be dissent between groups A and B about the semantics of a key term even if groups A and B have the same mean value on an attribute-dimension, but $\mathrm{A}$ has a much greater standard deviation with regard to this attribute than B. Similarly, significance analyses of statistical t-tests of mean values on an attributedimension tend to overstate relatively small semantic gaps, which are often not perceived by the concerned groups, due to the above mentioned intra-group variation. Consequently, in an earlier paper about Polish migration to Germany (Mueller 2011) the author proposed to measure the amount of potential conflict between immigrants and German residents by a simulation of the virtual encounters between the interviewed members of the two groups.

In this article, the above mentioned methodology of virtual encounters will first be applied to artificial data with controlled variation of means and standard deviations of the group-specific values on an attribute-dimension. These statistical experiments give a better understanding of the results produced by the proposed method. Subsequently it will be used in order to study the political semantics of left-wing orientation of individual respondents in the European Values Study (EVS 2008): for three exemplary countries, i.e. France, Sweden, and the UK, we attempt to investigate which political values are common to the left of these countries. 
For this purpose we analyze the citizen's attitudes towards political values social security and income equality. It turns out that both values are common elements in the self-definition of the left in the three countries. However, comparisons between the left and the right of each of these countries reveal that social security is in the UK and Sweden also an important value of the political right such that it cannot be considered as a specific value of the left.

The last finding points to another important use of the virtual encounter method: Intra-national comparisons between different groups. This opens the opportunity of comparing party-ideologies also at the national level. Moreover, different generations of supporters of a party may this way be compared. Assuming that these age-groups represent the respective ideologies of the time when they were young and politically socialized, the virtual encounter-method opens by these comparisons the possibility of exploring the historical change of party-ideologies.

\section{A THREE-STEP METHODOLOGY FOR ANALYZING SEMANTIC GAPS}

\subsection{Step one: Microsimulation of virtual interpersonal conflicts}

Conventional datasets with interview data for secondary analysis are generally monadic: each data-record describes just one single respondent. This is the standard format of most national or international surveys like e.g. the European Values Study EVS. Microsimulation of virtual interpersonal dissent or conflict, however, requires dyadic datasets containing data of two interacting persons $\mathrm{i}$ and $\mathrm{j}$. Fig. 2 describes the construction of such dyadic data-records by a random matching process, which can be implemented with conventional statistical software like SPSS (2015). Randomly permuted files of a group A and a group B are trimmed to the same length and stuck together such that the data of persons $i$ and $j$ are joined in the same dyadic data-record. Virtual conflicts $\mathrm{C}_{i, j}$ between $\mathrm{i}$ and $\mathrm{j}$ with regard to an attribute $\mathrm{X}$ can subsequently be determined by calculating the absolute differences $\left|\mathrm{X}_{i}-\mathrm{X}_{j}\right|$ between the attribute-values $\mathrm{X}_{i}$ and $\mathrm{X}_{j}$ of the two persons. As compared to the squared differences $\left(\mathrm{X}_{i}-\mathrm{X}_{i}\right)^{2}$ used in Euclidean metrics our approach has the advantage of being more sensitive to small differences between $X_{i}$ and $X_{j}$, which have the same weights as the large ones. The result of this random matching process corresponds in a certain way to the situation of modern urban societies where spontaneous encounters with strangers are more important than contacts with local neighbors (Toennies 1979). However, by selecting appropriate membership criteria of the two groups A and B it is possible to limit this randomness of virtual encounters and to make in this way all kinds of thought experiments, this being a typical advantage of social simulation. The resulting similarity or dissimilarity of the group members compared brings the proposed method of virtual encounters quite close to one-dimensional propensity score matching (Guo \& Fraser 2010), 
although the algorithms (microsimulation vs. logistic regression) as well as the purposes (thought experiments vs. correction of sampling bias) of the two methods are rather different.

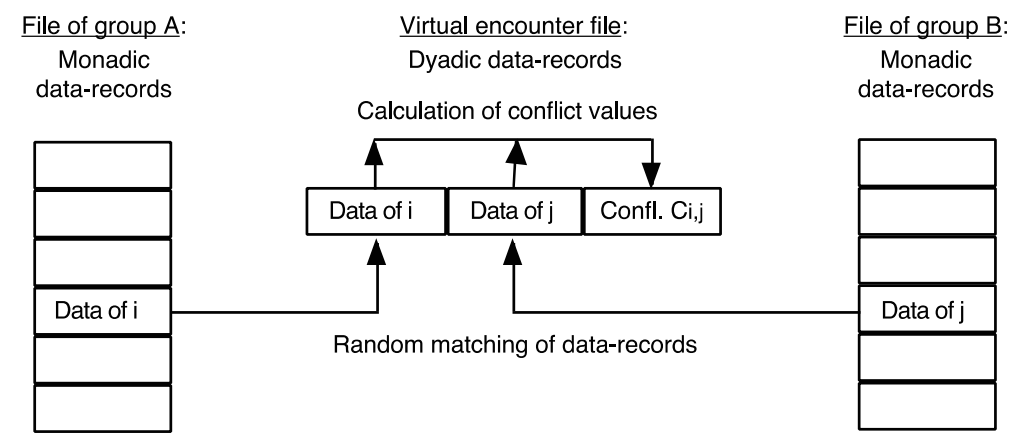

Legend: $\mathrm{i}$ and $\mathrm{j}$ are members of the groups $\mathrm{A}$ and $\mathrm{B}$. Conflict $\mathrm{Ci}, \mathrm{j}$ with regard to an attribute $\mathrm{X}=$ Value difference $\left|X_{i}-X_{j}\right|$. Source: Adapted from Mueller (2011), Fig. 2.

Fig. 2: The microsimulation of virtual value conflicts between pairs of persons.

\subsection{Step two: The transformation of virtual inter-group conflicts into mutual virtual group perceptions}

By the aggregation of simulated inter-personal virtual conflicts $C_{i, j}$ it becomes possible to calculate mean values of inter-group conflicts: most statistical programs like SPSS (2015) offer filters, which select pairs of persons with the right groupcharacteristics for this process of data-aggregation. The resulting conflict-scores are often hard to assess and consequently call for a reasonable benchmark or reference value in order to understand their real importance. The most natural one is the average intra-group conflict (Mueller 2011: 24), which corresponds to the idea of (political) homophily (Ackland \& Shorish 2014): people mainly communicate with peers and the resulting level of conflict influences their expectations with regard to other encounters, even if they are less frequent and more virtual. If this internal conflict of group A is lower than the inter-group conflict with group B, we assume that $A$ has a negative virtual perception of $B$ since interactions with $B$ produce a higher frequency of unpleasant experiences than the usual intra-group interactions (see Fig. 3). If the same intra-group conflict of $A$ is higher than the inter-group conflict with $\mathrm{B}$, group $\mathrm{A}$ is assumed to have a positive virtual perception of B. Finally, if the internal conflicts of A and the external with B are about the same, the virtual perception of $\mathrm{B}$ by $\mathrm{A}$ is neutral since interactions with $\mathrm{B}$ result for group members of A in a "normal" amount of dissent. 


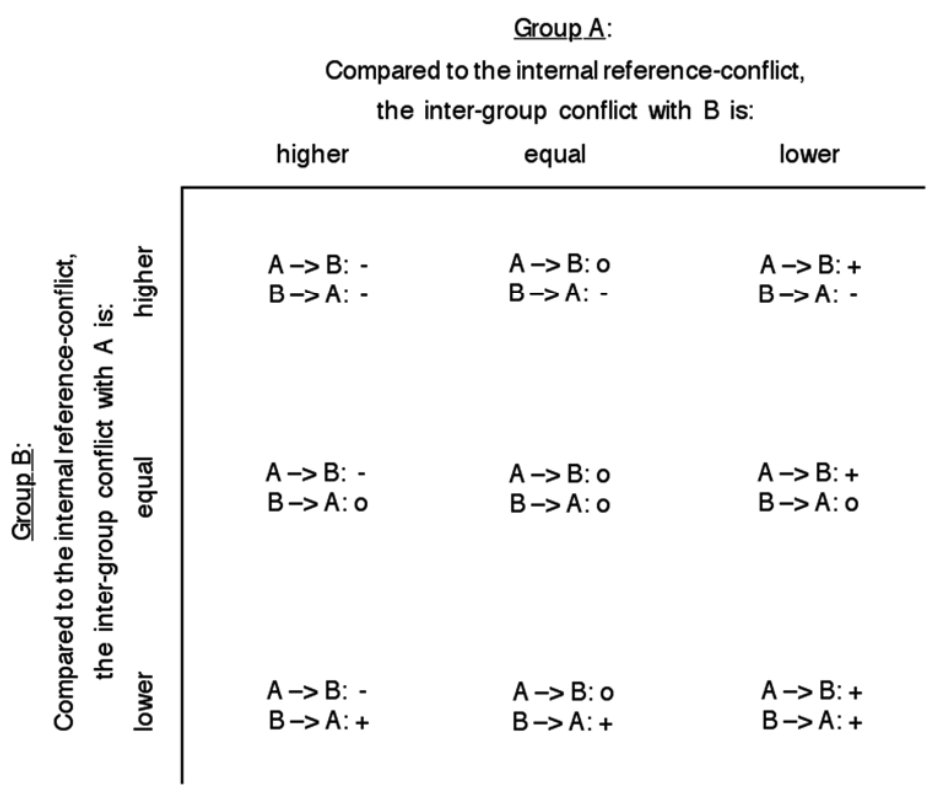

Legend: $A \rightarrow B$ : Perception of B by A; B $\rightarrow$ A: Perception of A by B; +: Positive perception; o: Neutral perception; -: Negative perception.

Fig. 3: The mutual virtual perceptions of two groups A and B as a consequence of their intra- and inter-group conflict.

The same inter-group interactions between A and B may for A have a quality other than that for B, since the two groups have different benchmarks defined by their internal levels of conflict. Consequently Fig. 3 shows not only 3 but 3 x $3=9$ different scenarios with sometimes quite contradictory outcomes: if e.g. B has a rather low and $A$ a rather high level of internal conflicts, the virtual interactions between $\mathrm{A}$ and $\mathrm{B}$ have for $\mathrm{B}$ a negative and for A a positive quality, as illustrated in Fig. 3 by the third column of row one.

\subsection{Step three: Network analysis of inter-group conflicts and semantic gaps}

Inter-group conflict can of course be represented as social networks (Wasserman \& Faust 2007): nodes stand for groups of persons with similar attitudes towards a key term and signed bi-directional arcs represent the mutual virtual perceptions of these groups, which are either positive, negative, or neutral, as defined in the previous Fig. 3 by internal and external levels of conflicts. Fig. 4 shows an example of such a network: it is the ideal network of the relations between the protagonists (pros) of a key term in two countries $\mathrm{N}$ and $\mathrm{M}$, and the respective 
national antagonists (cons) of the same key term. The semantic gap between the two national protagonists with regard to the key term is assumed to be close to zero, whereas the protagonists and antagonists are supposed to have considerable conflict regarding their attitudes towards the analyzed attribute of the given key term.

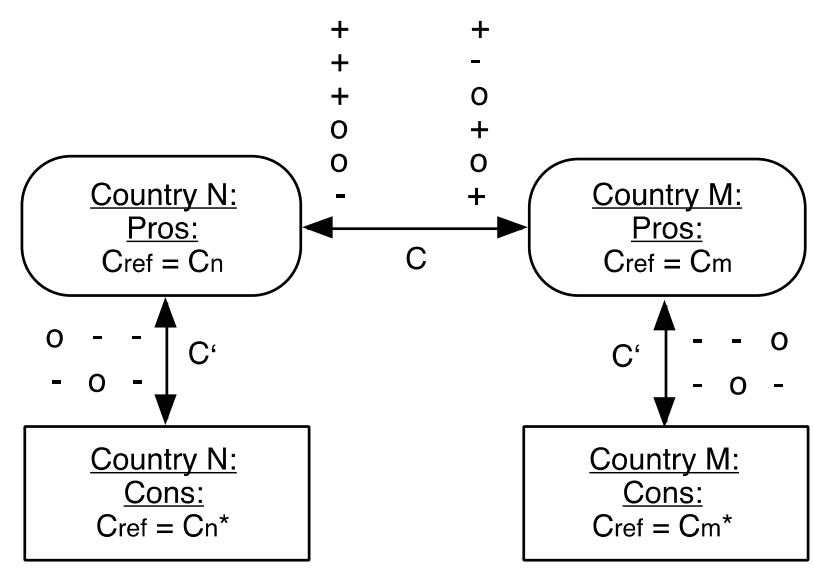

Legend: Pros, Cons: Protagonist and antagonists of the key term; $\mathrm{C}, \mathrm{C}^{\prime}=$ Inter-group conflicts about an attribute of the key term. Cref $=$ Reference conflict, with group-specific values $\mathrm{Cn}, \mathrm{Cn}^{*}, \mathrm{Cm}$, and $\mathrm{Cm}^{*}$; ,+ o, -: Pos., neutral, neg. perception.

Fig. 4: The possible virtual perceptions of the protagonists and antagonists of a key term which is specific and common to the pros in $\mathrm{N}$ and $\mathrm{M}$.

The latter difference is needed in order to ensure that the considered attribute of the key term is a specific, i.e. unique value of the protagonists and not a value that is also shared by the antagonists. Thus, in the best case, the virtual perceptions between the protagonists and the antagonists are mutually negative (see Fig. 4). This situation corresponds to the classical political cleavage of Rae \& Taylor (1970). It is, however, also admissible that only one virtual perception of the pros and cons is negative and the other zero (see Fig. 4), since in this situation the "average" relation between the mentioned groups is still negative. All other possible relations between the protagonists and the antagonists are absent from Fig. 4: they would imply too much correspondence between the pros and the cons such that the analyzed attribute would no longer be a specificity of the key term represented by the pros.

The first assumption of Fig. 4, i.e. the semantic correspondence of the key term for the two national groups of protagonists is best represented by the relation 
$(+,+)$ between the two groups (see Fig. 4): both groups have virtually a positive image of the other since the interaction between them results in less conflict than their respective intra-group interactions. The semantic gap regarding the key term is considered to be also relatively small if one group has a positive perception of the other while the reverse perception is neutral $(\operatorname{see}(+, 0)$ and $(o,+)$ relations of Fig. 4). Similar considerations hold for the relation (o, o), which points to a rather perfect semantic correspondence of the key term for the two protagonists: in this case internal and external levels of conflict are the same. Finally, we consider also the relations $(+,-)$ and $(-,+)$ between the pros of Fig. 4 as an indicator of semantic similarity: they point to situations where the interest of one group in the other compensates the virtual hostility of the second towards the first. As we shall see in the next section, this situation occurs if the meaning of the key term for the second group corresponds to the meaning within a subgroup of the first. Thus there is at least some similarity between the protagonists in the two countries. The remaining relations $(\mathrm{o},-),(-, \mathrm{o})$, and $(-,-)$ are not part of the relations between the pros of Fig. 4 since they would make the semantic gap of the key term too big, i.e. as big as between the pros and the cons.

\section{AN EXPLORATION OF THE METHOD WITH ARTIFICIAL DATA}

In order to gain additional insights into the method presented in the preceding section 2, we applied it to artificial random-data, which are divided into three groups with 3x200 uniformly distributed attitude values X (see Fig. 5). As compared to normal or other distributions, uniformly scattered attitudes $\mathrm{X}$ offer the advantage of clearly defined group-minima and -maxima. Ranges, overlaps, and inclusions of group ideologies are relatively well controlled this way and thus enable experiments with the following groups:

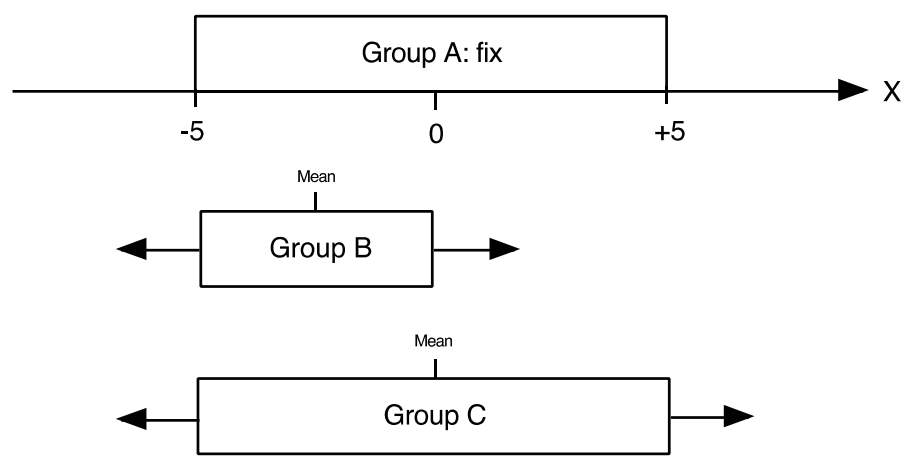

Fig. 5: The experimental design of Figs $6 a, b$ and 7 : Varying the means of groups $B$ and $C$ in relation to the fixed group $A$. 
a) Group $A$ has a fixed mean at $X=0$ and fixed minima and maxima at $X=-5$ and $\mathrm{X}=+5$. Its mean is used as the point 0 of the reference that determines the relative positions of two other groups $\mathrm{B}$ and $\mathrm{C}$.

b) Group $B$ has a smaller range of only 5 units between its maximum and minimum. Its mean varies in relation to the fixed mean of group A such that the amount of inter-group conflict with A can be studied. The result is a u-shaped curve, as depicted in Fig. 6a. Representing the inter-group conflict between A and $\mathrm{B}$, this curve is always above the confidence interval of the internal reference conflict of B. For mean values of B between b and b' the curve is however below the confidence interval of the reference conflict of group A. Thus between $b$ and $b$ ' group $B$ has a negative virtual image of $A$, whereas group A has a positive virtual perception of B.

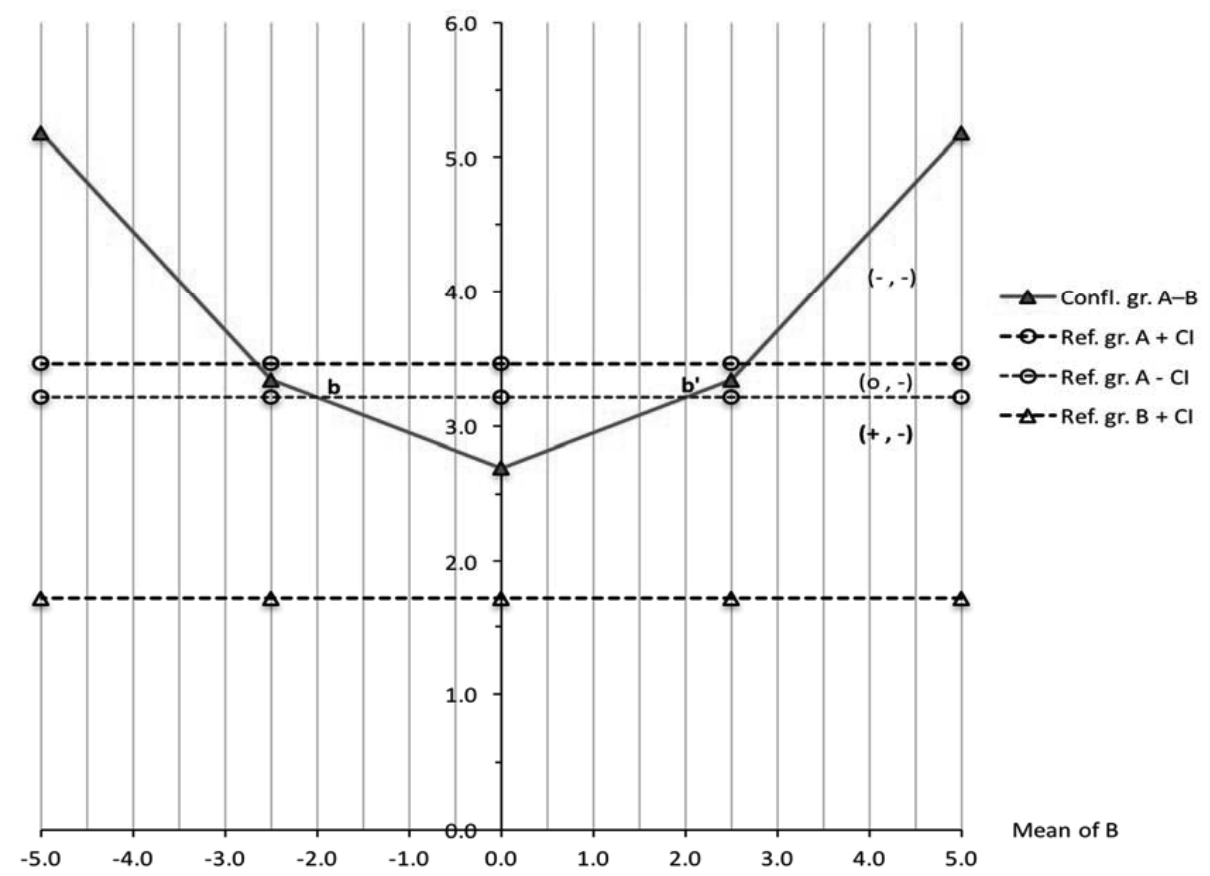

Legend: Confl. gr. A-B: Conflict between groups A and B; Ref. gr. A + CI: Upper limit of the $90 \%$-confidence interval of the reference conflict of A, which was calculated by a 1000 subsamples bootstrap; Ref. gr. A - CI: Lower limit of the previous $90 \%$-confidence interval; Ref. gr. B + CI: Upper limit of the $90 \%$-confidence interval of the reference conflict of B, which was calculated by a 1000 sub-samples bootstrap; [b,b']: Interval of semantic correspondence; $(+,-)$ : Perceptions of inter-group conflict by $\mathrm{A}$ and by $\mathrm{B}$, pointing to semantic correspondence; $(\mathrm{o},-),(-,-)$ : Perceptions of inter-group conflict by $\mathrm{A}$ and by B, pointing to a semantic gap.

Fig. 6a: Comparing meanings: Simulated ideological conflicts between groups $A$ and $B$, by varying mean values of $B$. 
This situation changes, when the mean of B is beyond the limits b or b' and consequently gets too far away from the mean value 0 of $A$ : in this situation A perceives $\mathrm{B}$ no longer as positive but rather as neutral or even negative. According to Fig. 4 this means that within the interval $\left[b, b^{\prime}\right]$ the meaning of the key term is the same for $\mathrm{A}$ and $\mathrm{B}$, whereas outside this it is different.

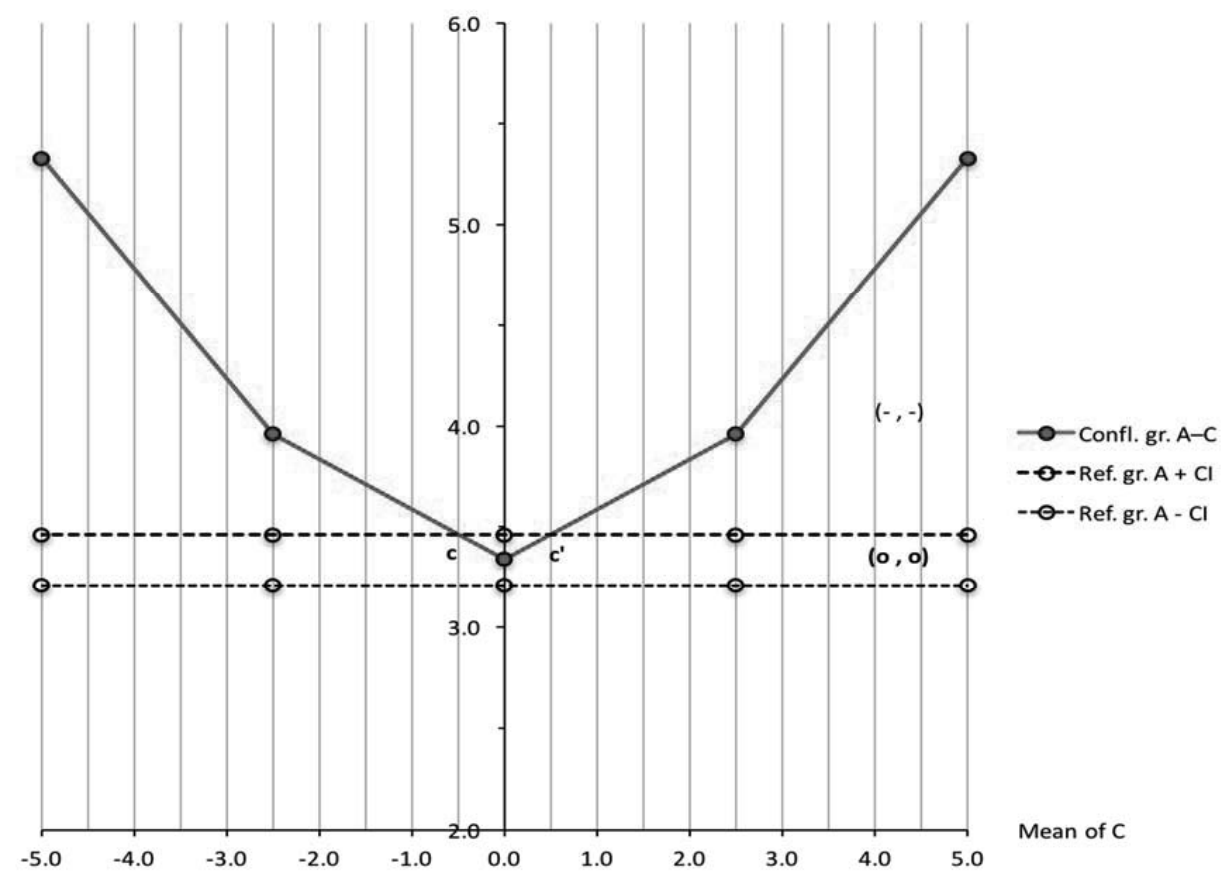

Legend: Confl. gr. A-C: Conflict between groups A and C; Ref. gr. A + CI: Upper limit of the $90 \%$-confidence interval of the reference conflict of A, which was calculated by a 1000 subsamples bootstrap (= Upper limit of the corresponding interval of C); Ref. gr. A - CI: Lower limit of the previous confidence interval of A (= Lower limit of the corresponding interval of $\mathrm{C}$ ); [c,c'c]: Interval of semantic correspondence; $(\mathbf{o}, \mathbf{o})$ : Perceptions of inter-group conflict by A and by $\mathrm{C}$, pointing to semantic correspondence; (-,-): Perceptions of inter-group conflict by $\mathrm{A}$ and by $\mathrm{C}$, pointing to a semantic gap.

Fig. 6b: Comparing meanings: Simulated ideological conflicts between groups A and $\mathrm{C}$, by varying mean values of $\mathrm{C}$.

c) Like group A, Group $C$ has a range of 10 units between its minimum and maximum values. Consequently its internal reference conflict and the related $90 \%$ confidence interval are the same as for $\mathrm{A}$. By varying the mean of $\mathrm{C}$ in relation to $\mathrm{A}$ it is possible to study the amount of virtual inter-group conflict between $\mathrm{A}$ and $\mathrm{C}$. The result is presented in Fig. $6 \mathrm{~b}$ and shows again a u-shaped conflict 
curve. Between the mean values $\mathrm{c}$ and c' the inter-group conflict between $\mathrm{A}$ and $\mathrm{C}$ is in the $90 \%$-confidence interval of the internal reference conflict of $\mathrm{A}$ and the corresponding identical interval of $\mathrm{C}$. Consequently the mutual virtual perceptions of $\mathrm{A}$ and $\mathrm{C}$ are both neutral. However, after moving the mean value of $\mathrm{C}$ beyond the limits $\mathrm{c}$ or c', the inter-group conflict is above the confidence intervals of the internal reference conflicts of $\mathrm{A}$ and $\mathrm{C}$ such that both virtual perceptions become negative. According to Fig. 4, this means that within the interval [c,c'] the meaning of the key term is the same for $\mathrm{A}$ and $\mathrm{C}$, whereas outside this it is different.

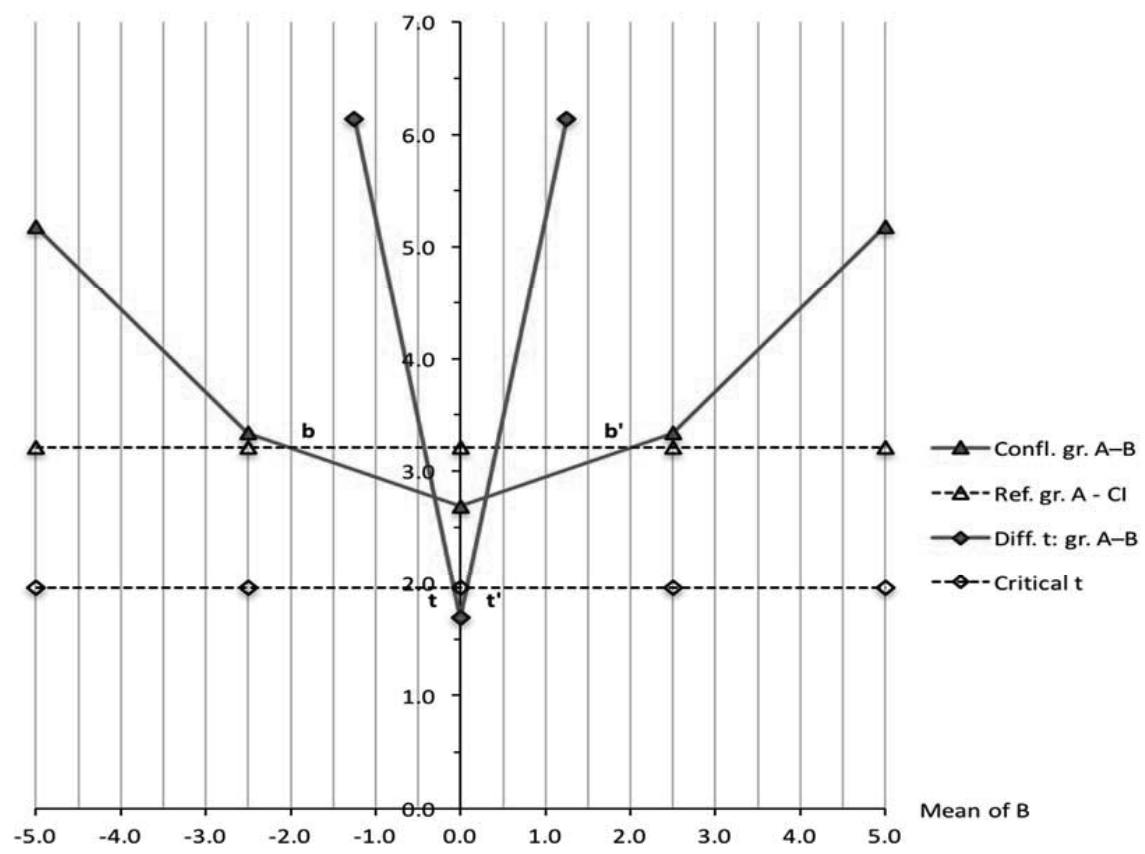

Legend: Confl. gr. A-B: Conflict between groups A and B; Ref. gr. A - CI: Lower limit of the $90 \%$-confidence interval of the reference conflict of $\mathrm{A}$, which was calculated by a 1000 subsamples bootstrap; Diff. t: gr. A-B: t-value of the difference between the mean scores of groups A and B; Critical t: Critical value of the previous t for a two-tailed test at the 5\% level; [b,b']: Interval of semantic correspondence based on virtual conflicts; [t,t't']: Interval of semantic correspondence based on statistical t-tests.

Fig. 7: Comparison of meanings: Conventional t-tests versus simulated virtual conflicts.

In sum, if the mean values of groups $\mathrm{A}, \mathrm{B}$, and $\mathrm{C}$ are the same $(=0)$, the key term has the same meaning for $\mathrm{A}$ and $\mathrm{B}$ as well as for $\mathrm{A}$ and $\mathrm{C}$, as we expect from traditional statistical analyses with t-tests. In the case of $\mathrm{A}$ and $\mathrm{C}$ with identical standard deviations, this correspondence of meanings is indicated by mutually neutral perceptions of the two groups. In the case of A and B, where 
B represents an ideological fraction of A, the correspondence of meanings is indicated by a mix of positive and negative virtual perceptions. In both situations the meaning of the key term is only dissimilar, if the difference of the group means goes beyond the respective thresholds b and b' or c and c'. These intervals of semantic correspondence are for the method of virtual encounters much larger than the confidence intervals of the conventional statistical t-tests. Fig. 7 illustrates this fact by a comparison between groups A and B. The interval $\left[b, b^{\prime}\right]$ is the same as in the previous Fig. 6a and thus based on virtual conflict. Its limits correspond to the critical t-values $t$ and ' ' for the equality of the means of A and B. However, the extremly small interval $\left[t, t^{\prime}\right]$ seems to overstate the differences in the meaning of the social or political key term. Thus the perceived difference of the key term based on simulated virtual conflicts is probably a more realistic approach than the purely statistical analysis of the original data.

\section{EMPIRICAL ANALYSES OF THE SEMANTICS OF LEFT IDEOLOGIES}

\subsection{Introduction}

This section aims at an exemplary analysis of the political semantics of left ideologies (Vincent 2010: chap. 4) in three European countries with rather different political traditions (Bartolini 2000: chap. 2, Weakliem \& Heath 1999, Svallfors 1999): France with a strong communist tradition and a centralist state; Sweden with a long history of social-democratic governments stressing the importance of social equality; and the United Kingdom (UK), which switched under prime minister Tony Blair to a postindustrial version of social democracy (New Labour). Differences between the countries mentioned could of course be analyzed by studying the official internet platforms of the respective left-wing political parties. Here we are more interested in the self-definition of leftist citizens. In the long run, their power as voters is more important for what leftwing politics really mean. Consequently we will focus on comparative surveydata about their political views.

A relatively useful data-source for our purpose is the European Values Study (EVS 2008). For the three countries mentioned it contains among other things information about the following three variables:

a) The self-positioning of the respondents on a political left-right scale (= variable V193). The corresponding EVS-interview question started with the remark that "in political matters people talk of the left and the right " and continued with the request to place ones "own views" on a 10-point scale with the anchors "left" (=1) and "right (=10) (EVS 2008: Master Questionnaire). The statistical distribution of the original data (see Fig. 8) suggests the exclusion of the value $\mathrm{V} 193=5$, which is not only the modus of the distribution but also a remarkable 


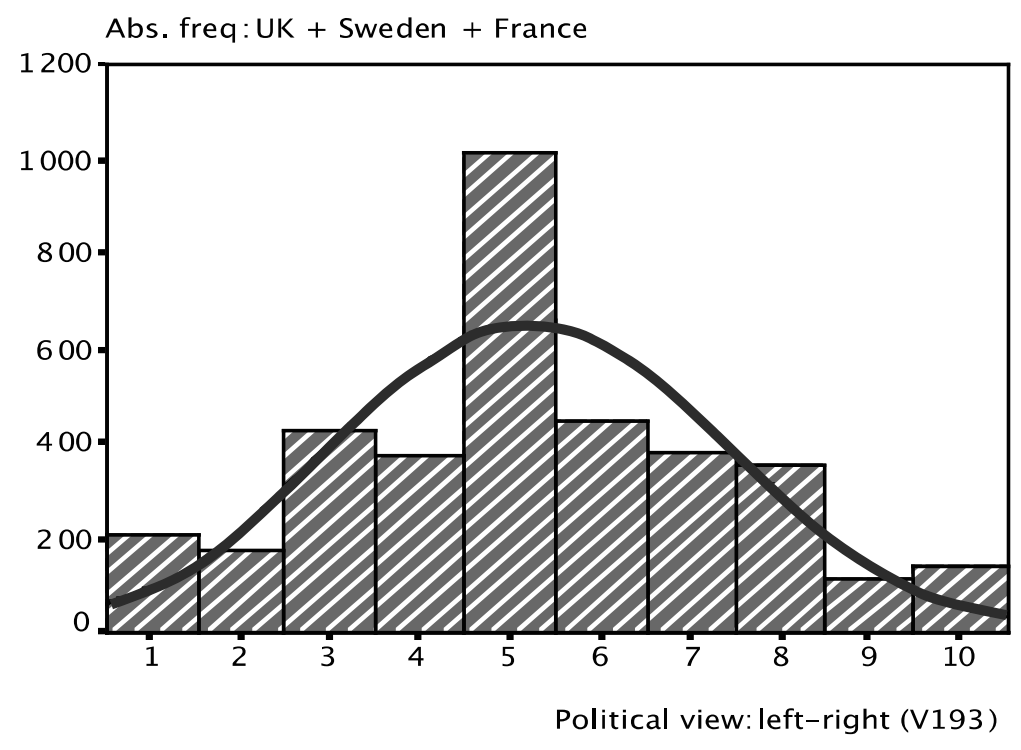

Fig. 8: The statistical distribution of the analyzed respondents on the left-right continuum of variable V193 (see EVS 2008).

outlier far beyond the maximum of the Gaussian bell-curve. This category in the middle probably contains many politically uninterested or uninformed voters (Rodon 2015, Scholz \& Züll 2016). The remaining data are divided into two groups: V193 $\leq 4$ as partisans of the left and V193 $\geq 6$ as partisans of the right. These are rather broad categories, which are sufficiently robust to cope with the imprecision of the self-identification on the left-right continuum, as reported by Bauer \& al. (2017).

b) The personal approval of social security (= variable V194) as an alternative to responsibility for one's own wellbeing, which is also measured on a 1 to 10 scale: people were asked whether "the state (or the individuals) should take more responsibility for providing for themselves" (EVS 2008: Master Questionnaire). As usual, it is assumed that the scale has interval properties and the semantic distance between adjacent values is always the same.

c) The subjective importance of income equality, with values from 1 (lowest) to 10 (highest). It corresponds to $11-\mathrm{V} 198$, i.e. the inverse of the original EVSvariable V198, which has a different polarity than the previous variable (b). In the original EVS-interview respondents were asked whether "there should be greater incentives for individual efforts" or "incomes should be made more equal" (EVS 2008: Master Questionnaire). As in the case of the previous scale it is assumed that $11-\mathrm{V} 198$ has the properties of an interval scale. 
According to empirical and theoretical work of Gelissen (2002: 68, 81, 104, 119) social security and income inequality are both correlated with the selfidentification of respondents with left ideologies. In addition a study by Bauer \& al. (2017, Fig. 10) about Germany mentions also solidarity and justice as values of the left. However with EVS (2008) as the main data source of this section these values are difficult to measure. Thus, in view of its illustrative character we confine the analysis of this section to the previously mentioned attributes, social security and income equality.

On the basis of 1000 randomly permuted individuals from France, Sweden and the UK we first built six dyadic files (see Fig. 2), which matched nationals of the following pairs of countries: France - Sweden, France - UK, Sweden - UK, France - France, Sweden - Sweden, and UK - UK. Thus each of the resulting dyadic files contained 1000 cases. This data base allowed us to calculate absolute value differences with regard to social security and income equality for pairs of persons selected according to two different types of political orientation: partisans of the left (V193 $\leq 4)$ and of the right $(\mathrm{V} 193 \geq 6)$ who are assumed to represent the respective ideologies. The results of these calculations could be used in order to estimate the mean values and the respective 90\%-confidence intervals of the virtual conflicts between and within the countries analyzed. Confidence intervals were calculated by a bootstrap-procedure (Mooney \& Duval 1993) implemented in SPSS (2015) that processed 1000 subsamples. The results of all these statistical calculations are presented in Figs. 9 and 10.

\subsection{Results for the left political value social security}

Fig. 9 suggests that social security is a rather universal value of the European left: there seems to be consensus about this value between the French, the British, and the Swedish left: the inter-group conflict always corresponds to the intra-group conflict such that the mutual virtual perceptions of the three left parties are neutral (zero). Nonetheless it is problematic to consider social security as a central element of the ideology of the left in the countries mentioned. Certainly in the UK and to a lesser extent also in Sweden there is no virtual conflict between the left and the right about this political issue, which means that the support for social security has in these countries spread to the political right and is consequently not a specific value of the left. As the cleavage-like value conflict between the left and the right in France demonstrates, it is only in this country that social security is a specific endeavor of the political left. 


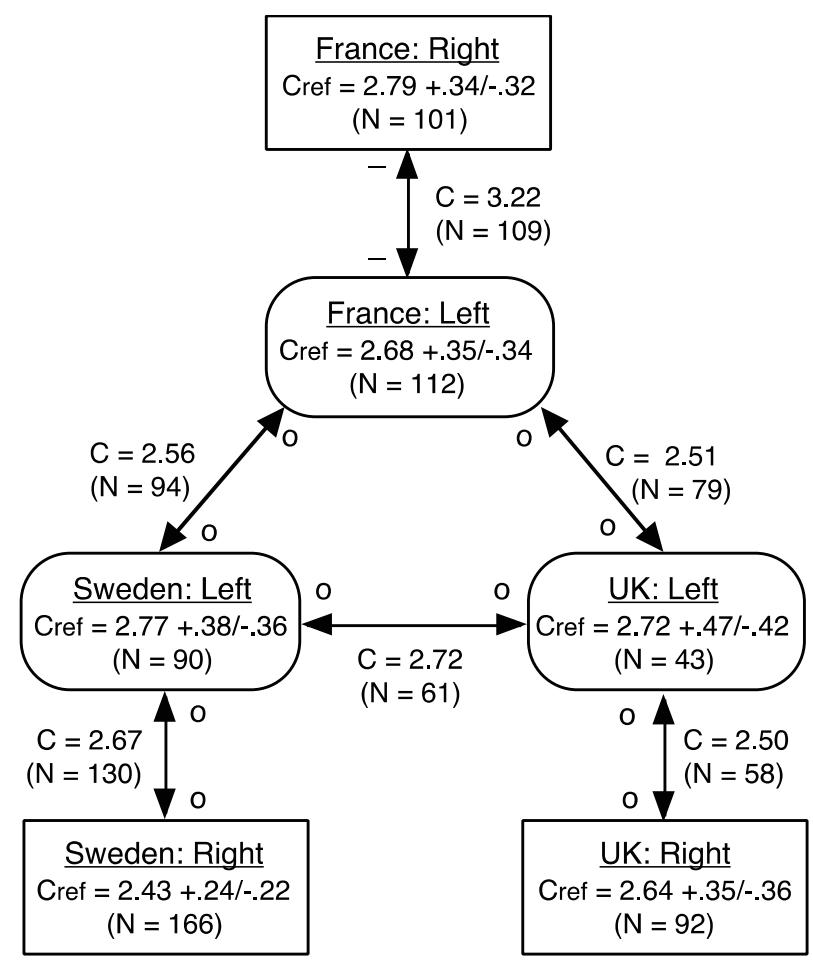

Legend: C: Inter-group conflict; Cref +e/-e' = Reference conflict (see text) with upper limit e and lower limit e' of a 90\%-confidence interval, which was calculated by a 1000 subsamples bootstrap; + relation: $\mathrm{C}<\mathrm{Cref}-\mathrm{e}$; - relation: $\mathrm{C}>\mathrm{Cref}+\mathrm{e}$; o relation: $\mathrm{C} \approx \mathrm{Cref}+\mathrm{e} /$-e'; $\mathrm{N}=$ number of cases.

Fig. 9: Simulated virtual conflicts with regard to social security.

\subsection{Results for the left political value income equality}

Contrary to the case of social security, income equality is a specific value of the political left. According to Fig. 10, the relations between the left and the right are conflictive in all three countries analyzed, with at least one negative virtual perception of the opposite party. As a consequence of this comparatively high specificity of income equality, the virtual conflicts between the left and the right of all three countries are greater for income equality than for social security (see inter-group conflicts of Figs 9 and 10). In addition, income equality is a common value of the left in these countries: inter-group conflicts between the French and the British left are comparable to the respective internal benchmarks and thus point to a high value consensus between these groups. Moreover, the French and 
the British left both have a positive virtual image of the Swedish left, whereas the reverse perception is neutral (see Fig. 10). According to Fig. 4 this implies a value consensus between the British and the Swedish as well as between the Swedish and the French left.

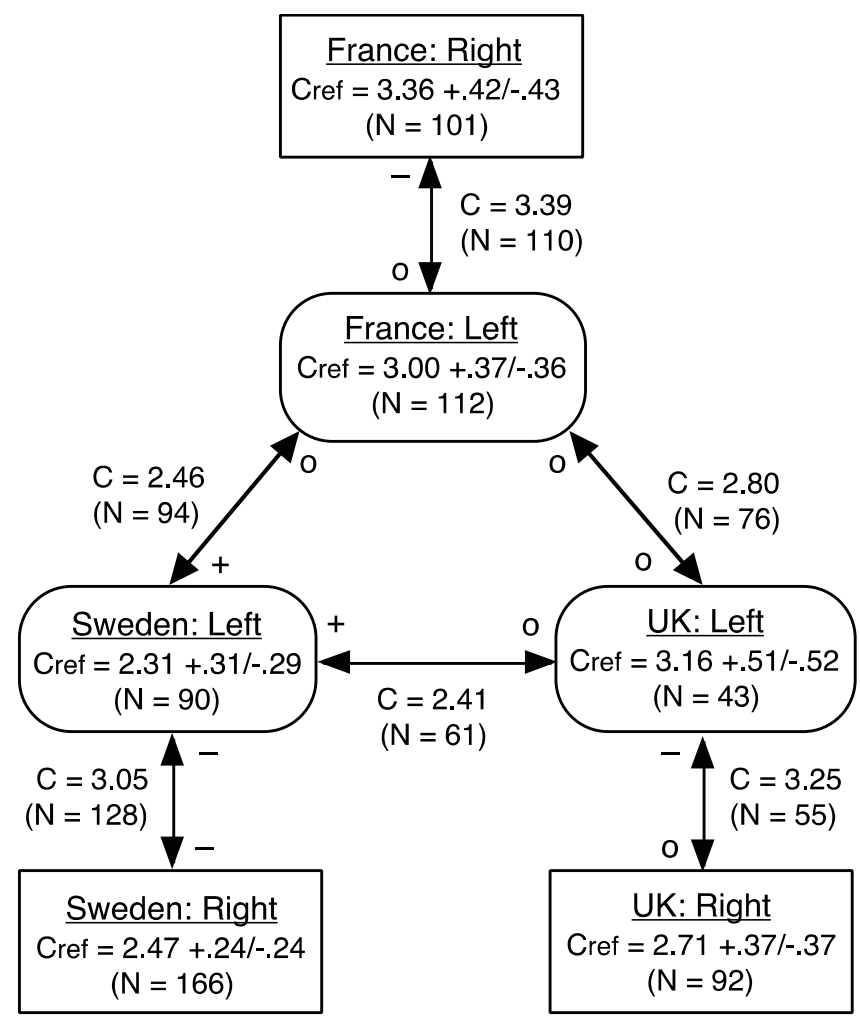

Legend: Like legend of Fig. 9, but for income equality.

Fig. 10: Simulated virtual conflicts with regard to income equality.

\section{CRITICAL SUMMARY AND OUTLOOK}

In section 4 of this article we wanted to answer the question, whether left ideology has the same meaning in different countries. In order to answer this question we simulated virtual encounters between persons who participated in the European Values Study (EVS 2008). In general, this method has the advantage of giving a more realistic picture of inter- and intra-group conflict than the traditional 
statistical methods based on group-means of conventional data sets. By comparing the same virtual inter-group conflict with two different group-specific internal conflict references, it is possible to identify conflict asymmetries (see Fig. 3). Moreover, these intra-group references relativize small but semantically unimportant variations in the meaning of the social or political key terms analyzed: the approach proposed in this article tends to annihilate such differences, even if they are statistically significant (see Fig. 7).

By means of the microsimulation method mentioned above we were able to compare the French, British, and Swedish left with regard to two values as examples: income equality and social security. It seems that only income equality is a common and specific value of the left in these countries (see Fig. 10). The other tested attribute, i.e. social security, is a shared but generally not very specific value of the left in the political systems analyzed (see Fig. 9). This corresponds to the findings of a study by Bauer et al. (2017: Fig. 10), where Germans were asked open-ended interview questions about the meaning of the term "left" in politics.

These empirical findings may however be influenced by the following limitations in the research design of the present study:

a) The number of attributes of the key term, which in a follow-up study should certainly be enlarged in order to give a really complete picture of the shared and specific values of the left: interview questions about solidarity and justice could e.g. be used to gain more refined empirical results about left ideologies (see Bauer $\&$ al. 2017, Fig. 10). However, as mentioned earlier, they are not directly available in the EVS (2008) analyzed in this article and thus require other datasets.

b) The number of countries: There are many other countries in the European Values Study, which could have been included in this analysis. Countries in Eastern Europe with a Soviet communist past, or liberal welfare states with a lack of social security (Esping-Andersen 1993: chap. 1, Gelissen 2002: chap. 2) would be examples of great interest for such additional analyses.

c) The number of observations in the dyadic files: for technical reasons it was limited to 1000 pairs of persons. This is only a very small fraction of the 1 to 4 million pairs of respondents that can be constructed with 1 to 2 thousand original interviews per nation. Hence, it would be possible to increase the sample size of the current study in order to reduce the width of the confidence intervals of the simulated conflicts (Cramer \& Howitt 2004: 32-35), which in turn would increase the statistical significance of the network relations of Figs. 9 and 10. This could be performed by a computer program that creates a theoretically unlimited sequence of pairs of random numbers, which identify the individuals to be matched and compared.

The virtual encounter method described in this article is not only suited for international but also for intra-national comparisons of the semantics of political 
values. For such comparisons there are generally even more data available than for international analyses. Intra-national simulations may e.g. shed light on the ideological differences between similar parties like the traditional and the new populist right. They might help to understand the ideological differences between the German AfD and the Bavarian CSU, where the proposed method takes the voters and not the politicians as the real experts of these ideologies. Similarly, by virtual encounter simulations one might compare different generations of representatives of ideologies. Is there for example a virtual conflict between the feminists born before 1980 and the younger generations? And if so, how will this conflict evolve in the future since there is a secular trend in the demographic weights of the two groups. Tackling the latter question with the virtual encounter method shows another advantage of this type of social simulation: it answers "what-if" questions represented by interesting political and social scenarios.

\section{NOTES}

1 This article is an updated and enlarged version of an earlier working paper of the same author, published as Mueller (2016).

\section{REFERENCES}

Ackland, R., \& Shorish, J. (2014). Political Homophily on the Web. In M. Cantijoch \& al. (Eds), Analysing Social Media Data and Web Networks (pp.25-46). Houndmills: Palgrave Macmillan.

Bartolini, S. (2000). The Political Mobilization of the European Left, 1860-1980: The Class Cleavage. Cambridge: Cambridge University Press. https://doi.org/10.1017/ CBO9780511521560

Bauer, P. \& al. (2017). Is the Left-Right Scale a Valid Measure of Ideology? Political Behaviour, 39(3), 553-583.

Callon, M., Courtial, J.-P., \& Penan, H. (1993). La scientométrie. Paris: Presses Universitaires de France.

Cramer, D., \& Howitt, D. (2004). The Sage Dictionary of Statistics. London: Sage Publications. https://doi.org/10.4135/9780857020123

Crow, I. (2006). Ecological Fallacy. In V. Jupp (Ed.), The Sage Dictionary of Social Research Methods (pp.82-83). London: Sage Publications.

de Bellis, N. (2009). Bibliometrics and Citation Analysis. Toronto: Scarecrow Press.

Esping-Andersen, G. (1993). The Three Worlds of Welfare Capitalism. Cambridge: Polity Press.

ESS (2015). European Social Survey: Overview. http://www.europeansocialsurvey.org/ (accessed on 11/5/2015).

EVS (2008). European Values Study: Survey 2008. http://www.europeanvaluesstudy.eu/ page/survey-2008.html (accessed on 6/5/2017).

Gelissen, J. (2002). Worlds of Welfare, Worlds of Consent? Public Opinion on the Welfare State. Leiden: Brill. 
Guo, S., \& Fraser, M. (2010). Propensity Score Analysis. Los Angeles: Sage.

Hantrais, L. (2007). Contextualization in Cross-National Comparative Research. In L. Hantrais \& al. (Eds), Cross-National Research Methodology \& Practice (pp.3-18). London: Routledge.

Harkness, J., Van de Vijver, F., \& Mohler, P. (Eds) (2003). Cross-Cultural Survey Methods. Hoboken: John Wiley.

Harkness, J. (2007). Improving the Comparability of Translations. In R. Jowell \& al. (Eds), Measuring Attitudes Cross-Nationally: Lessons from the European Social Survey (pp.79-94). London: Sage Publications. https://doi.org/10.4135/9781849209458.n4

Harkness, J. \& al. (Eds) (2010). Survey Methods in Multinational, Multiregional, and MulticulturalContexts. Hoboken:JohnWiley.https://doi.org/10.1002/9780470609927

ISSP (2015). International Social Survey Programme: Overview. http://www.issp.org/ (accessed on 11/5/2015).

Lewis, P. (2000). Political Parties in Post-Communist Eastern Europe. London: Routledge.

Mooney, Ch., \& Duval, R. (1993). Bootstrapping: A Nonparametric Approach to Statistical Inference. Newbury Park: Sage. https://doi.org/10.4135/9781412983532

Mueller, G. (2011). Microsimulation of Virtual Encounters: A New Methodology for the Analysis of Socio-Cultural Cleavages. International Journal of Microsimulation 4(1), 21-34.

Mueller, G. (2016). On the Use of Interview Data for the Microsimulation of Ideological Conflicts: An Analysis of the Political Cleavages of the European Left. (Working Paper SES 471). Fribourg: Faculty of Economics and Social Sciences of the University of Fribourg.

Rae, M. \& Taylor, M. (1970). The Analysis of Political Cleavages. New Haven: Yale University Press.

Rodon T. (2015). Do All Roads Lead to the Centre? The Unresolved Dilemma of Centrist Self-Placement. Int. J. of Public Opinion Research 27(2), 177-196. https:// doi.org/10.1093/ijpor/edu028

Saris, W., \& Gallhofer, I. (2007). Can Questions Travel Successfully? In R. Jowell \& al. (Eds), MeasuringAttitudes Cross-Nationally: Lessonsfrom the European SocialSurvey (pp.53-78). London: Sage Publications. https://doi.org/10.4135/9781849209458.n3

Scholz, E., \& Zuell, C. (2016). Methodological Aspects of Central Left-Right Scale Placement in a Cross-national Perspective. Bulletin de Méthodologie Sociologique 132(1), 44-57. https://doi.org/10.1177/0759106316662588

Smith, T. \& al. (2009). Methods for Assessing and Calibrating Response Scales across Countries and Languages. In M. Sasaki (Ed.), New Frontiers in Comparative Sociology (pp. 45-94). Leiden: Brill.

SPSS (2015). http://www-01.ibm.com/software/analytics/spss/products/statistics/ (accessed on 3/12/2015).

Svallfors, S. (1999). The Class Politics of Swedish Welfare Politics. In G. Evans (Ed.), The End of Class Politics? Class Voting in Comparative Context (pp.203-230). Oxford: Oxford University Press. https://doi.org/10.1093/0198296347.003.0008

Toennies, F. (1979). Gemeinschaft und Gesellschaft (Community and Society). Darmstadt: Wissenschaftliche Buchgesellschaft. 
Vincent, A. (2010). Modern Political Ideologies (3rd edition). Chichester: Wiley-Blackwell.

Wasserman, S., \& Faust, K. (2007). Social Network Analysis. Cambridge: Cambridge University Press.

Weakliem, D., \& Heath, A. (1999). The Secret Life of Class Voting: Britain, France, and the United States Since the 1930s. In G. Evans (Ed.), The End of Class Politics? Class Voting in Comparative Context (pp.97-136). Oxford: Oxford University Press. https://doi.org/10.1093/0198296347.003.0005 